\title{
Changes for codeine
}

\section{Darren M Roberts}

Clinical pharmacologist

The Canberra Hospital

Associate professor

Australian National

University Medical School

Canberra

Staff specialist

Alcohol and Drug Services

Clinical Pharmacology and

Toxicology

St Vincent's Hospital

Sydney

\section{Suzanne Nielsen}

Senior research fellow

National Drug and Alcohol

Research Centre

UNSW Sydney

Pharmacist

Drug and Alcohol Service

South Eastern Sydney Local

Health District

Sydney

\section{Keywords}

codeine, drug abuse, drug regulation, Therapeutic Goods Administration

Aust Prescr 2018;41:2-3

https://doi.org/10.18773/ austprescr.2018.006

First published

23 January 2018
From 1 February 2018 codeine is being rescheduled to a prescription-only medicine.

Codeine is widely used in Australia, often in combination with other drugs. In 2013, more than 27 million packs of codeine-containing analgesic products were supplied by pharmacies, and $56 \%$ of these sales were over-the-counter without a prescription. ${ }^{1}$ National sales data show that over-thecounter codeine-containing analgesics account for $37 \%$ of all opioid purchases in the community. ${ }^{2}$

Codeine is metabolised to morphine but there is marked interindividual variability in metabolism which contributes considerable differences in analgesic effects. Due to the opioid effects of codeine, people can become dependent with regular use.

The proportion of people seeking opioid substitution treatment for codeine dependence in Australia rose from $2.7 \%$ in 2014 to $4.6 \%$ in 2016. A study in Sydney reported that codeine was the sole substance used by $39 \%$ of patients with a pharmaceutical opioid dependence and $83 \%$ of these patients were using only over-the-counter codeine. ${ }^{3}$ At a drug dependence unit in South Australia, the annual incidence of codeine dependence requiring intervention increased from 31 people in 2003 to 174 in 2014. The estimated cost of treating 30 patients with codeine-related admissions in one Adelaide hospital was over $\$ 1$ million. ${ }^{4}$ In 2013 the National Drug Strategy Household Survey reported that $33 \%$ of the people who had misused pharmaceuticals had used over-the-counter codeinecontaining analgesics. ${ }^{5}$ This increased to $75 \%$ in $2016 .{ }^{6}$

The long-term use of codeine-containing products, particularly in supra-therapeutic doses, risks complications from each of the co-formulated ingredients such as paracetamol and ibuprofen. Paracetamol can cause hepatotoxicity and ibuprofen has adverse cardiovascular, gastrointestinal and renal effects which can be life-threatening.

The Therapeutic Goods Administration (TGA) has reviewed the availability of codeine in response to reports of misuse and toxicity. In 2010 it removed the pharmacy-only (Schedule 2) listing for codeinecontaining analgesics and restricted pack sizes to five days supply. In 2016 it proposed rescheduling all codeine-containing products to prescription only (Schedule 4).

Submissions to the TGA supporting rescheduling included addiction specialists reporting increasing numbers of patients with codeine dependence, pharmacists expressing frustration with the difficulty managing challenging patients, and members of the public speaking of families being destroyed by codeine addiction. Each group identified the ready availability of codeine over-the-counter as a contributor. In some cases it was being used non-medically or in excessive doses, in others it was being used to treat chronic pain with minimal oversight by a health professional. ${ }^{7}$

Those arguing against codeine rescheduling included patients using codeine regularly, people with limited access to GPs, and community pharmacists. ' During the consultation period, the Pharmacy Guild of Australia introduced an opt-in database (MedsASSIST) to demonstrate the feasibility of pharmacists monitoring over-the-counter sales of codeine in real time.

After more than 18 months of consultation, the TGA announced that all codeine-containing products would become Schedule 4 from 1 February 2018. This decision was made because of the likelihood of significant public health benefits, based on the evidence of harm due to dependence on widely accessible, over-thecounter codeine-containing analgesics. This harm was contrasted with evidence that these products in recommended doses provided little additional benefit when compared to other analgesics without codeine.

Consumers and health professionals have questioned whether rescheduling codeine will reduce harm. ${ }^{8}$ The TGA and professional societies have therefore issued guidance to health practitioners and the public. ${ }^{9}$ It was hoped that individuals who had developed dependence would seek medical assistance before codeine was up-scheduled. However, due to stockpiling, shame, fear of stigma, and self-denial, it is possible that some people with codeine-use disorder will emerge after February 2018.

Australian data show that the typical codeine user is well-educated and employed, and that codeineuse disorder is a largely hidden problem.,10 People with substance use disorders are not always readily identified by stereotyped external features or behaviours, and such depictions can be detrimental in the context of substance use already being a highly stigmatised condition. They are often hesitant to disclose substance use, if indeed they acknowledge that their use is problematic.

It is anticipated that pain relief will be a key reason for people seeking prescriptions for codeine or other opioids. As always, the assessment of pain requires a careful history and examination rather than simply prescribing. A potential benefit of rescheduling codeine is that it will direct attention to the clinical 
assessment and management of pain and the hazards of opioids. Clear messages for patients from health professionals about the relative efficacy of non-opioid analgesics available over-the-counter may also help address their concerns."

The assessment of pain involves asking about the use of over-the-counter analgesics. The possibility that the patient is taking doses exceeding the usual daily maximum should be explored in a non-judgemental and patient-centred manner. The Government has proposed a national real-time prescription monitoring program, which in some jurisdictions may include the monitoring of Schedule 4 opioids. This may provide additional information to support the clinical assessment. In cases where the use of high doses is suspected, patients should be asked about symptoms of opioid withdrawal and symptoms due to co-formulated drugs, such as gastrointestinal toxicity due to ibuprofen.

When codeine dependence is identified, mental health and physical comorbidities that may have contributed to codeine use require careful assessment and treatment. This may include testing for anaemia, liver or renal dysfunction and electrolyte abnormalities. Patients with moderate-severe signs, symptoms or laboratory abnormalities may require specialist input to guide treatment. Presentations with any of these features provide a useful opportunity to review the current management plan and discuss treatment options, including consideration of referral if mental health symptoms have contributed to escalating codeine use.
The reduced availability of codeine can be anticipated to reduce harms for many who are codeine dependent. Opioid substitution treatment (methadone or buprenorphine/naloxone) offers the opportunity to promote physical, social and psychological stability for patients who are willing to receive it. Both methadone and buprenorphine are effective in treating pharmaceutical opioid dependence. An Australian case series found that buprenorphine/ naloxone is commonly prescribed for people who are codeine dependent. ${ }^{3}$ This treatment may have advantages over methadone in terms of reduced risk of respiratory depression, greater experience with its use in the treatment of codeine dependence, and more flexibility with unsupervised (take-home) dispensing. Expanding buprenorphine treatment in primary care may be an ideal way to help patients with codeine dependence. Anticipating and preparing for the changes to codeine availability in 2018 is as critical for patients as it is for health professionals. $<$
Suzanne Nielsen is supported by a National Health and Medical Research Council research fellowship (\#1132433). The National Drug and Alcohol Research Centre at UNSW Sydney is supported by funding from the Australian Government under the Substance Misuse Prevention and Service Improvements Grant Fund. She is a named investigator on untied educational grants from Indivior (no salary funding received), and provided education to health professionals on the identification and treatment of codeine dependence for Indivior.

\section{REFERENCES}

1. Gisev N, Nielsen S, Cama E, Larance B, Bruno R, Degenhardt L. An ecological study of the extent and factors associated with the use of prescription and over-the-counter codeine in Australia. Eur J Clin Pharmacol 2016;72:469-94. https://doi.org/10.1007/s00228-015-1995-8

2. Degenhardt L, Gisev N, Cama E, Nielsen S, Larance B, Bruno R. The extent and correlates of community-based pharmaceutical opioid utilisation in Australia. Pharmacoepidemiol Drug Saf 2016;25:521-38. https://doi.org/10.1002/pds.3931

3. Nielsen S, Murnion B, Dunlop A, Degenhardt L, Demirkol A, Muhleisen P, et al. Comparing treatment-seeking codeine users and strong opioid users: findings from a novel case series. Drug Alcohol Rev 2015;34:304-11. https://doi.org/ 10.1111/dar.12224

4. Mill D, Johnson JL, Cock V, Monaghan E, Hotham ED. Counting the cost of over-the-counter codeine containing analgesic misuse: a retrospective review of hospital admissions over a 5 year period. Drug Alcohol Rev 2017. [Epub ahead of print] https://doi.org/10.1111/dar.12595

5. Australian Institute of Health and Welfare. National Drug Strategy Household Survey detailed report 2013. Drug statistics series no. 28. Cat. no. PHE 183. Canberra: AlHW; 2014. https://www.aihw.gov.au/reports/illicit-use-of-drugs/ ndshs-2016-detailed/contents/table-of-contents [cited 2017 Dec 4]
6. Australian Institute of Health and Welfare. National Drug Strategy Household Survey detailed report 2016: detailed findings. Drug statistics series no. 31 Cat. no. PHE 214. Canberra: AlHW; 2017. https://www.aihw.gov.au/reports/illicituse-of-drugs/ndshs-2016-detailed/contents/table-of-contents [cited 2017 Dec 4]

7. Therapeutic Goods Administration. Public submissions on scheduling matters referred to the ACMS\#17 March 2016 (codeine). www.tga.gov.au/schedulingsubmission/public-submissions-scheduling-matters-referred-acms17-march2016-codeine [cited 2017 Dec 4]

8. McCoy J, Bruno R, Nielsen S. Attitudes in Australia on the upscheduling of over-the-counter codeine to a prescription-only medication. Drug Alcohol Rev 2017 Jun 8. [Epub ahead of print] https://doi.org/10.1111/dar.12568

9. Therapeutic Goods Administration. Codeine information hub. Changes to patient access for medicines containing codeine. 2017 Sep 8. https://www.tga.gov.au/codeine-info-hub [cited 2017 Dec 4]

10. Nielsen S, Cameron J, Lee N. Characteristics of a nontreatment-seeking sample of over-the-counter codeine users: implications for intervention and prevention. J Opioid Manag 2011;7:363-70.

11. NPS MedicineWise. Over-the-counter codeine: changes to supply. www.nps.org.au/medical-info/clinical-topics/over-the-counter-codeinechanges-to-supply\#insights [cited 2017 Dec 4].

\section{FURTHER READING}

Abbott PV. Medical management of dental and oral pain. Aust Prescr 2007;30:77-91 https://doi.org/10.18773/austprescr.2007.044

Cohen ML. Principles of prescribing for persistent non-cancer pain. Aust Prescr 2013;36:113-5. https://doi.org/10.18773/austprescr.2013.044

James J. Dealing with drug-seeking behaviour. Aust Prescr 2016;39:96-100. https://doi.org/10.18773/austprescr.2016.022

Maher CG, Williams C, Lin C, Latimer J. Managing low back pain in primary care. Aust Prescr 2011;34:128-32. https://doi.org/10.18773/austprescr.2011.069
McDonough M. Safe prescribing of opioids for persistent non-cancer pain Aust Prescr 2012;35:20-4. https://doi.org/10.18773/austprescr.2012.008 Health NS. Chronic pain management. Information for medical practitioners. Updated 2016 Feb 11. http://www.health.nsw.gov.au/pharmaceutical/doctors/ Pages/chronic-pain-medical-practitioners.aspx [cited 2017 Dec 4]

The Pharmacy Guild of Australia. Codeine upscheduling. 2017. www.guild.org.au/ resources/proposed-codeine-up-scheduling [cited 2017 Dec 4] 